\title{
Adsorption and thermal dehydrogenation of ammonia on $\mathrm{Ru}(1121)$
}

Cite as: J. Chem. Phys. 115, 4306 (2001); https://doi.org/10.1063/1.1390523

Submitted: 27 February 2001 . Accepted: 14 June 2001 . Published Online: 20 August 2001

K. Jacobi, Y. Wang, C. Y. Fan, and H. Dietrich

\section{ARTICLES YOU MAY BE INTERESTED IN}

Dynamics of ammonia decomposition on Ru(0001)

The Journal of Chemical Physics 113, 6882 (2000); https://doi.org/10.1063/1.1310662

Electron energy loss spectroscopy of ammonia on Ru(001)

The Journal of Chemical Physics 88, 5225 (1988); https://doi.org/10.1063/1.454597

Interaction of hydrogen with nitrogen atoms chemisorbed on a Ru(0001) surface

The Journal of Chemical Physics 102, 1432 (1995); https://doi.org/10.1063/1.468930
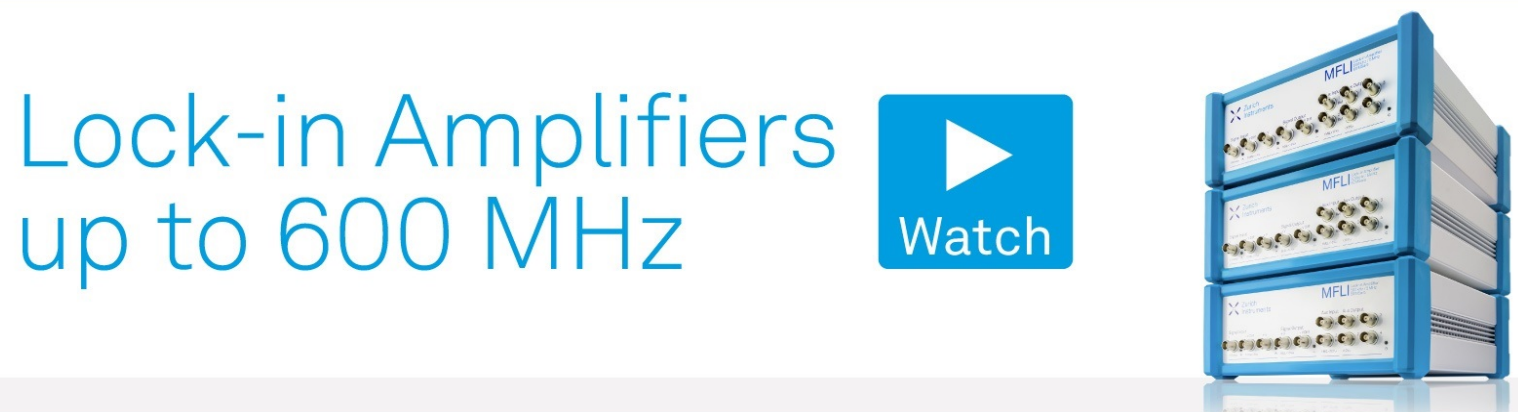

J. Chem. Phys. 115, 4306 (2001); https://doi.org/10.1063/1.1390523

115,4306

(c) 2001 American Institute of Physics. 


\title{
Adsorption and thermal dehydrogenation of ammonia on $\mathrm{Ru}(112 \overline{1})$
}

\author{
K. Jacobi, ${ }^{\text {a) }}$ Y. Wang, C. Y. Fan, and H. Dietrich \\ Fritz-Haber-Institut der Max-Planck-Gesellschaft, Faradayweg 4-6, D-14195 Berlin, Germany
}

(Received 27 February 2001; accepted 14 June 2001)

\begin{abstract}
Adsorption and thermal dehydrogenation of $\mathrm{NH}_{3}$, adsorbed at $80 \mathrm{~K}$ on the open $\mathrm{Ru}(11 \overline{2} 1)$ surface, was studied using high-resolution electron energy-loss spectroscopy (HREELS) and thermal desorption spectroscopy (TDS). For the $\mathrm{NH}_{3}$ monolayer, a strong dipole-active mode is found at 15 meV which is newly assigned to $T_{z}$, the frustrated-translation mode perpendicular to the surface of $\mathrm{NH}_{3}$ bonding with the nitrogen atom to the Ru surface. Increasing the temperature, $70 \%$ of $\mathrm{NH}_{3}$ desorbs before a channel for dehydrogenation opens at about $280 \mathrm{~K}$. The remaining $30 \%$ decomposes completely during further warming to $470 \mathrm{~K}$. The dehydrogenation of $\mathrm{NH}_{3}$ gives rise to four peaks in the $\mathrm{H}_{2}$ TDS which are assigned to desorption of coadsorbed hydrogen at $220 \mathrm{~K}$ and three dehydrogenation reaction steps at 320,360, and $420 \mathrm{~K}$ in accordance with HREELS. The reaction intermediates $\mathrm{NH}_{2}$ and $\mathrm{NH}$ are identified through HREELS. In a new interpretation $\mathrm{NH}_{2}$ is characterized by intense modes at $163 \mathrm{meV}$ (rocking) and at $189 \mathrm{meV}$ (scissoring). Using a maximum entropy algorithm six frequencies for $\nu(\mathrm{Ru}-\mathrm{N})$ were resolved at 46, 50, 58, 61, 69, and $75 \mathrm{meV}$. (C) 2001 American Institute of Physics. [DOI: 10.1063/1.1390523]
\end{abstract}

\section{INTRODUCTION}

Ru-based catalysts may become the second-generation industrial catalysts for $\mathrm{NH}_{3}$ synthesis ${ }^{1}$ which, according to general belief, proceeds via stepwise recombination of chemisorbed atomic nitrogen and hydrogen as it was found for iron-based catalysts earlier. ${ }^{2}$ Thus, one expects $\mathrm{NH}$ and $\mathrm{NH}_{2}$ to occur as reaction intermediates. Not very much was known about these species, their preparation, and spectroscopic characterization, till now.

Early experiments on the adsorption of $\mathrm{NH}_{3}$ on $\mathrm{Ru}(0001)$ have been carried out by Danielson et al. ${ }^{3,4} \mathrm{NH}_{3}$ desorbs reversibly for adsorption temperatures below $300 \mathrm{~K}$ and the desorption is completed at about $350 \mathrm{~K}$. Two different desorption states are distinguished in the monolayer regime. ${ }^{5}$ Dissociation of $\mathrm{NH}_{3}$ on $\mathrm{Ru}(0001)$ has been achieved by electron bombardment ${ }^{4}$ or by exposing the surface to large fluences of $\mathrm{NH}_{3}$ for surface temperatures maintained above $300 \mathrm{~K} .^{6,7}$ The vibrational frequencies for mono-, second-, and multi-layer $\mathrm{NH}_{3}$ on $\mathrm{Ru}(0001)$ have been profoundly reviewed by Parmeter et al. ${ }^{8}$ which have suggested that $\mathrm{NH}_{3}$ adsorbs at an on-top site.

Upon heating, dehydrogenation of $\mathrm{NH}_{3}$ has been observed on a stepped $\operatorname{Ru}(1,1,10)$ surface by Egawa et al. ${ }^{7}$ From x-ray photoelectron spectroscopy (XPS) they concluded that $\mathrm{NH}_{x}(x=1,2)$ is formed after heating to $300 \mathrm{~K}$. A high density of $\mathrm{NH}_{x}$ species could be detected only under flow conditions at $380 \mathrm{~K}^{7}$ Decomposition of $\mathrm{N}_{2} \mathrm{H}_{4}$ on $\mathrm{Ru}(0001)$ resulted in rather complex vibration spectra in high-resolution energy-loss spectroscopy (HREELS) from which fingerprints for $\mathrm{NH}$ and $\mathrm{NH}_{2}$ were derived. ${ }^{9}$ For $\mathrm{Ni}(110)$, held at $344 \mathrm{~K}$ in an ambient pressure of 2 $\times 10^{-8}$ mbar $\mathrm{NH}_{3}$, a mode at $188 \mathrm{meV}$ was assigned to the $\mathrm{NH}_{2}$ scissoring mode. ${ }^{10}$ The analysis was hampered, how-

${ }^{\text {a)} E l e c t r o n i c ~ m a i l: ~ j a c o b i @ f h i-b e r l i n . m p g . d e ~}$ ever, through co-adsorbed $\mathrm{NH}_{3}$ and CO. Synthesis of $\mathrm{NH}_{3}$ from adsorbed $\mathrm{N}$ and $\mathrm{H}$ has been studied by Shi et al. ${ }^{11}$

Recently, we have shown that $\operatorname{Ru}(11 \overline{2} 1$ ) (see Fig. 1) is suited to study the dehydrogenation of $\mathrm{NH}_{3}$ giving rise to $\mathrm{NH}$ and $\mathrm{NH}_{2}$, the expected decomposition products. ${ }^{12}$ Our analysis was based on the assumption that $\mathrm{NH}$ is characterized by a NH bending mode of high energy (165 meV, 1350 $\mathrm{cm}^{-1}$ ) on $\mathrm{Ru}$ surfaces. ${ }^{9-11}$ In a more recent study Staufer et al., ${ }^{13}$ have performed calculations of $\mathrm{NH}$ on a variety of different small $\mathrm{Ru}$ clusters of 4-7 Ru atoms using densityfunctional theory. NH was found to be energetically favored on a threefold-hollow site at perpendicular orientation. With respect to our analysis, the most important point is their finding that the bending mode frequencies lie below about 100 $\mathrm{meV}$ for all models. The conclusion was that any imaginable error in the calculations could never lead to a frequency as high as $165 \mathrm{meV}$. Therefore, conclusions based on the according assignment in Refs. 9-11 have to be revised in the future.

In this contribution we discuss the vibrational spectra of ammonia and newly assign the frustrated-translation mode perpendicular to the surface. Also, we present the data on $\mathrm{NH}_{3}$ dehydrogenation in greater detail than before and revise our recent assignment ${ }^{12}$ of the $\mathrm{NH}$ and $\mathrm{NH}_{2}$ intermediates resulting in a more consistent interpretation.

\section{EXPERIMENT}

The experiments were carried out in an ultrahigh vacuum apparatus with a base pressure of $3 \times 10^{-11} \mathrm{mbar}$ which was achieved by a pumping line consisting of a Tisublimation pump, a turbo-molecular pump with magnetic suspension (Leybold, NT340M), a drag pump (Balzers, TCP015), and a diaphragm pump. The apparatus consisted of two chambers - the upper chamber contained an argon ion gun, a quadrupole mass spectrometer, and a low-energy elec- 

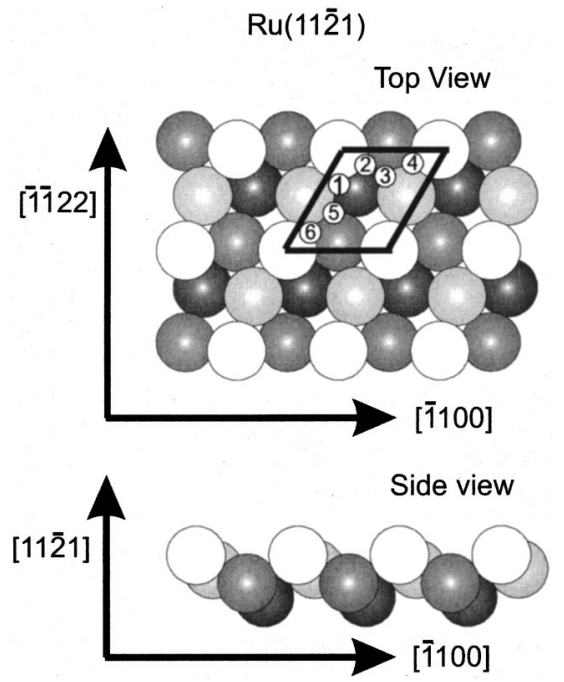

FIG. 1. Top view and side view of the unrelaxed Ru(11리) surface including the four topmost layers. The top layer is light, the layers below are indicated more dark with increasing depth.

tron diffraction (LEED) optics, - the lower chamber housed an Ibach-type HREEL spectrometer ${ }^{14}$ for recording vibrational spectra. The two chambers were separated by a valve, in order to keep the lower chamber at a pressure of 3 $\times 10^{-11}$ mbar during preparation of the sample in the upper chamber. HREEL spectra were taken at an angle of incidence of $60^{\circ}$ with respect to the surface normal in specular geometry. The primary energy was $2.5 \mathrm{eV}$ and the energy resolution was set to $3.8 \mathrm{meV}$.

The mass spectrometer was used to perform TDS measurements with a heating rate of $3 \mathrm{~K} \mathrm{~s}^{-1}$. For this purpose the sample was positioned in front of a short stainless-steel tube with a diameter of about the sample size so that the ionizer of the mass spectrometer accepted only molecules desorbing from the sample surface. The signal for $\mathrm{e} / \mathrm{m}$ ratios of 2,14 , 17 , and 28, were recorded quasi-simultaneously to follow the desorption of $\mathrm{H}_{2}, \mathrm{~N}_{2}, \mathrm{NH}_{3}$, and $\mathrm{CO}$. The cracking pattern of $\mathrm{N}_{2}$ and $\mathrm{CO}$ differ at mass 14 and, therefore, allow to distinguish between $\mathrm{CO}$ and $\mathrm{N}_{2}$ desorption.

The $\mathrm{Ru}(11 \overline{2} 1)$ sample was clamped at two edges between two tungsten wires and heated by electron bombardment from the back side. The crystal temperature was measured by a $\mathrm{Ni}-\mathrm{Cr} / \mathrm{Ni}$ thermocouple spot welded on the upper edges of the sample. Cleaning of the surface was achieved by repeated cycles of sputtering and annealing at $1560 \mathrm{~K}$. The cleanliness of the surface was verified by LEED and HREELS. The surface exhibited a sharp $1 \times 1$ pattern in LEED. The exposure is given in units of Langmuir (1 Langmuir $\left.=1.33 \times 10^{-6} \mathrm{mbar} \mathrm{s}\right)$. Absolute coverage could only be estimated by comparison with $\mathrm{Ru}(0001)$ since no coverage reference exists for $\mathrm{Ru}(11 \overline{2} 1)$ up to now. The identification of adsorbates by HREELS is a rather difficult task on $\mathrm{Ru}(11 \overline{2} 1)$. These difficulties arise from the high reactivity and the sparse information on the vibrational modes on this surface. A contamination like $\mathrm{CO}$ give rise to many different vibrational losses which are in part due to CO dissociation, similarly as observed for $\operatorname{Ru}(11 \overline{2} 0) .{ }^{15}$



FIG. 2. TD spectra of $\mathrm{NH}_{3}$ (mass 17) for a sequence of $\mathrm{NH}_{3}$ exposures on $\mathrm{Ru}(11 \overline{2} 1)$ at $80 \mathrm{~K}$. The inset shows the integrated TDS intensity vs exposure.

\section{RESULTS}

\section{A. TDS of ammonia and its dehydrogenation products}

In Fig. 2 TD spectra of $\mathrm{NH}_{3}$ are shown for different exposures at $80 \mathrm{~K}$. After an exposure of $0.3 \mathrm{~L} \mathrm{NH}_{3}$, only a very small desorption peak occurs at about $300 \mathrm{~K}$. (Note that this spectrum is scaled up by a factor of 10.) Increasing the exposure to $0.4 \mathrm{~L}$, the desorption peak at $300 \mathrm{~K}$ substantially gains intensity indicating that $\mathrm{NH}_{3}$ starts desorbing. As we will demonstrate by HREELS below, the first $0.3 \mathrm{~L}$ of $\mathrm{NH}_{3}$ dissociate. At an exposure of $1 \mathrm{~L}$ the $\alpha$ state is completely filled and the $\beta$ state starts emerging at about $140 \mathrm{~K}$. After exposing the surface to $5 \mathrm{~L} \mathrm{NH}_{3}$, the $\beta$ state is fully developed with a peak at $125 \mathrm{~K}$, and the $\gamma$ state appears at $100 \mathrm{~K}$. Using a frequency factor of $\nu=10^{13} \mathrm{~s}^{-1}$, the activation energies for the desorption from the $\beta$ state $\left(E_{d}=30 \mathrm{~kJ} / \mathrm{mol}\right)$ and from the $\gamma$ state $\left(E_{d}=25 \mathrm{~kJ} / \mathrm{mol}\right)$ can be calculated. Due to its strong broadening we cannot derive an activation energy for the $\alpha$ state. The TD spectra from $\mathrm{Ru}(11 \overline{2} 1)$ are quite similar to the TD spectra of $\mathrm{NH}_{3}$ from $\mathrm{Ru}(0001){ }^{5}$ Therefore, we attribute the $\beta$ state to the desorption of second-layer ammonia and the $\gamma$ state to the desorption of multilayer ammonia. On $\mathrm{Ru}(0001)$ Benndorf et al. ${ }^{5}$ distinguished between two $\alpha$ states, which may also be recognized from our spectra (denoted as $\alpha_{1}$ and $\alpha_{2}$ ).

In order to follow the decomposition in more detail, we have studied TD spectra of the products hydrogen and nitrogen simultaneously. Figure 3 exhibits-together in the same figure- the TD spectra of mass 2 for $\mathrm{H}_{2}$ and mass 14 for $\mathrm{N}_{2}$ for several exposures of $\mathrm{NH}_{3}$ at $80 \mathrm{~K}$. Mass 14 was chosen in order to differentiate between $\mathrm{CO}$ and $\mathrm{N}_{2}$. At an exposure of $0.04 \mathrm{~L}$, the TD spectrum of mass 2 exhibits a broad peak at $340 \mathrm{~K}$. From its size and the according HREEL spectra ${ }^{16}$ we conclude that it is mainly due to hydrogen adsorbed from the residual gas which cannot be avoided for this reactive $\mathrm{Ru}$ surface even at a background pressure of $3 \times 10^{-11} \mathrm{mbar}$. The $\mathrm{H}_{2}$ spectra, taken after exposing the sample to $0.3 \mathrm{~L}$ $\mathrm{NH}_{3}$, can be divided into the following four parts: $\alpha-\mathrm{H}_{2}$ $(420 \mathrm{~K}), \beta-\mathrm{H}_{2}(360 \mathrm{~K}), \gamma-\mathrm{H}_{2}(320 \mathrm{~K})$, and $\delta-\mathrm{H}_{2}(220 \mathrm{~K})$. 


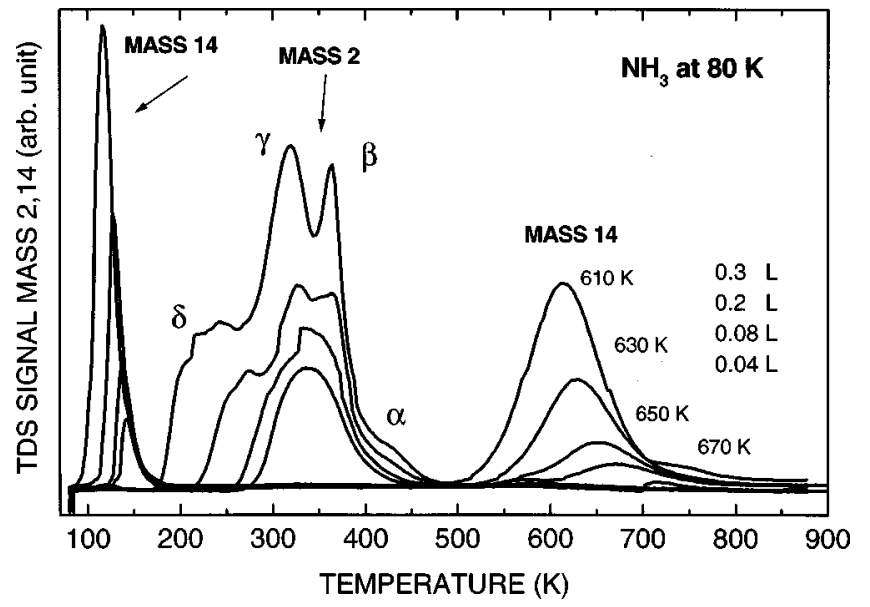

FIG. 3. TD spectra for a sequence of $\mathrm{NH}_{3}$ exposures on $\mathrm{Ru}(11 \overline{2} 1)$ at $80 \mathrm{~K}$. The pressure increase for $\mathrm{N}_{2}$ (mass 14) and $\mathrm{H}_{2}$ (mass 2) was recorded simultaneously. Parameter is the $\mathrm{NH}_{3}$ exposure in units of Langmuir (1 $\mathrm{L}=1.33$ mbar $\times \mathrm{s})$.

If one increases the exposure of $\mathrm{NH}_{3}$, only the TD spectrum of mass 17 changes (see Fig. 2), while the spectra of mass 2 and mass 14 remain unchanged, i.e., larger amounts of $\mathrm{NH}_{3}$ do not dissociate.

As indicated by the TD spectra of mass 14 in Fig. 3, the adsorption of molecular nitrogen is observed below $140 \mathrm{~K}$. This molecular nitrogen is most likely due to decomposition of $\mathrm{NH}_{3}$ in the dosing line. Between 670 and $610 \mathrm{~K}, \mathrm{~N}_{2}$ is observed associatively desorbing in a second-order process. Compared to $\operatorname{Ru}(0001)^{17}$ and $\operatorname{Ru}(10 \overline{1} 0)^{18}$ the thermal stabilization of $\mathrm{N}$ is smaller on $\mathrm{Ru}(11 \overline{2} 1)$, i.e., $\mathrm{N}_{2}$ desorbs at a lower temperature.

In order to examine whether the $\mathrm{H}_{2}$ TD spectra of Fig. 3 are typical for $\mathrm{H}_{2}$ desorption from a $\mathrm{H}$-covered $\mathrm{Ru}(11 \overline{2} 1)$ surface, we performed TDS experiments after dosing $\mathrm{H}_{2}$ which are discussed elsewhere. ${ }^{16}$ From this study we show in Fig. 4 one $\mathrm{H}_{2}$ TD spectrum after an exposure of $0.8 \mathrm{~L} \mathrm{H}_{2}$ at $80 \mathrm{~K}$, and compare it with the $\mathrm{H}_{2}$ TD spectrum following a $0.3 \mathrm{~L} \mathrm{NH}_{3}$ exposure at $80 \mathrm{~K}$. Note that the intensities in Fig.

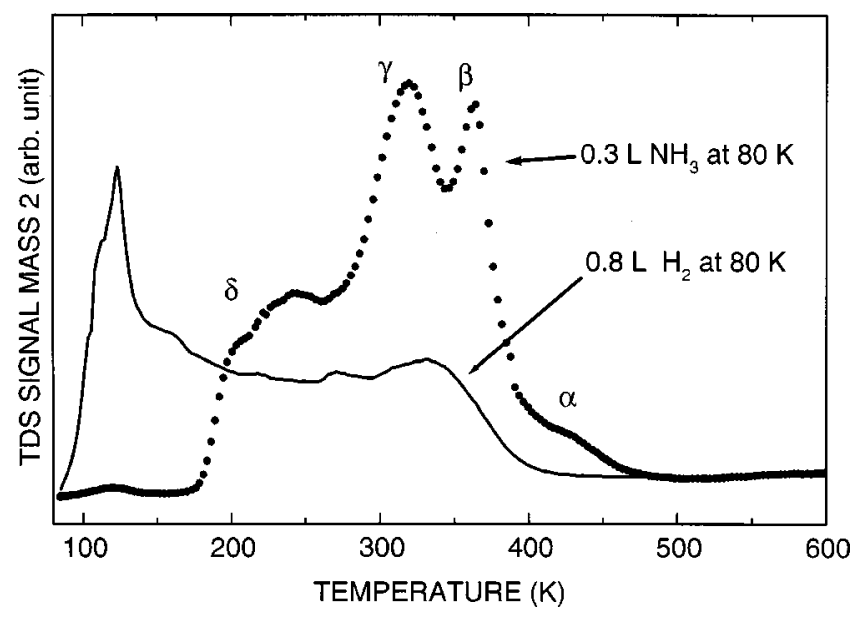

FIG. 4. TD spectra for $0.8 \mathrm{~L} \mathrm{H}_{2}$ on $\mathrm{Ru}(11 \overline{2} 1)$ at $80 \mathrm{~K}$ (full curve). For comparison the TD spectrum of mass 2 for an exposure $0.3 \mathrm{~L} \mathrm{NH}_{3}$ at $80 \mathrm{~K}$ is shown. Note that the intensities are scaled.

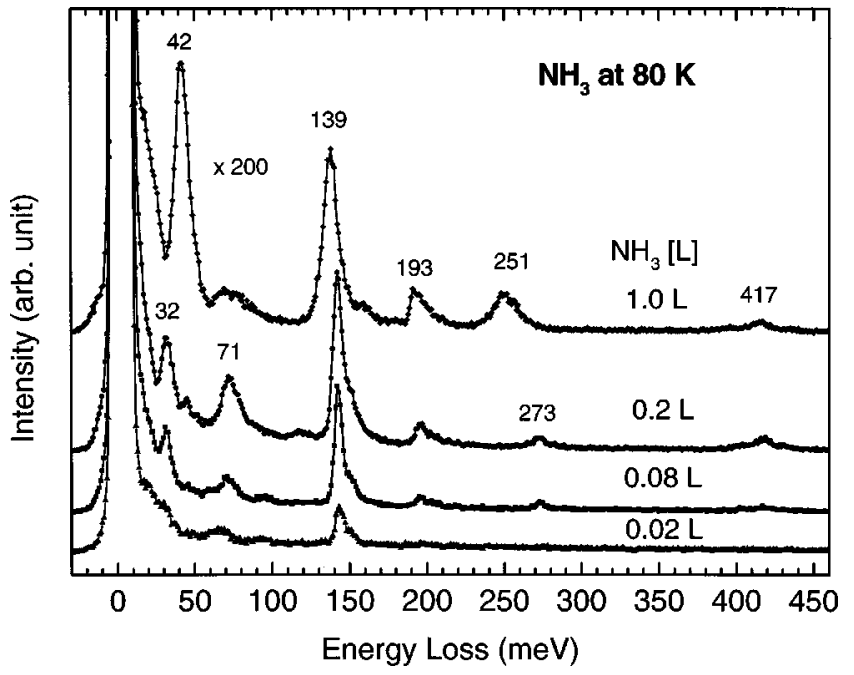

FIG. 5. HREEL spectra for a sequence of $\mathrm{NH}_{3}$ exposures on $\mathrm{Ru}(11 \overline{2} 1)$ at 80 $\mathrm{K}$. The primary energy of the electrons was $2.5 \mathrm{eV}$. All spectra were recorded in specular geometry with an angle of incidence of $60^{\circ}$ with respect to the surface normal. Parameter is the $\mathrm{NH}_{3}$ exposure in units of Langmuir (L).

4 are scaled. A comparison of the $\mathrm{H}_{2}$ TDS integrals leads to the following result: From a $\mathrm{NH}_{3}$ exposure of $0.3 \mathrm{~L}$, which carries a $\mathrm{H}_{2}$ equivalent of $0.45 \mathrm{~L} \mathrm{H}_{2}$, about three times more $\mathrm{H}_{2}$ desorbs than from chemisorbed hydrogen in the same temperature interval. Therefore, we conclude that the $\mathrm{H}_{2}$ signals in Fig. 3 are mainly due to $\mathrm{NH}_{3}$ decomposition. With the help of HREELS we will demonstrate in the following that three out of the four hydrogen states are due to dehydrogenation of $\mathrm{NH}_{3}$ rather than to adsorption of atomic hydrogen.

\section{B. HREELS of ammonia}

HREEL spectra following $\mathrm{NH}_{3}$ adsorption at $80 \mathrm{~K}$ (Fig. 5) exhibit the evolution of the typical vibrations of chemisorbed $\mathrm{NH}_{3}$ as assigned and summarized in Table I. Most indicative for $\mathrm{NH}_{3}$ is the umbrella mode at around $140 \mathrm{meV}$. Co-adsorbed $\mathrm{N}_{2}$ is observed with losses at $273 \mathrm{meV}$ for the internal stretch mode $\nu(\mathrm{N}-\mathrm{N})$, and at $32 \mathrm{meV}$ for the external stretch mode of $\mathrm{N}_{2}$ against the surface $\nu\left(\mathrm{Ru}-\mathrm{N}_{2}\right)$. For exposures larger than $0.4 \mathrm{~L}, \nu(\mathrm{N}-\mathrm{N})$ shifts to $250 \mathrm{meV}$ and $\nu\left(\mathrm{Ru}-\mathrm{N}_{2}\right)$ to $42 \mathrm{meV}$ due to interaction with $\mathrm{NH}_{3}$. The vibrational features for the monolayer saturate at $1 \mathrm{~L}$. The vibrational energies, found for the $\mathrm{NH}_{3}$ multilayer after an exposure of $5 \mathrm{~L} \mathrm{NH}_{3}$, are in good agreement with data from the literature ${ }^{8}$ and will not been discussed here. When the $\mathrm{NH}_{3}$ monolayer builds-up, the umbrella mode $\delta\left(\mathrm{NH}_{3}\right)$ softens with coverage as shown in Fig. 6. This effect was shown to be due to a Stark shift in the electric field of the static $\mathrm{NH}_{3}$ dipoles within the adlayer on a $\mathrm{Ru}(0001)$ surface. ${ }^{19}$

After dosing $\mathrm{NH}_{3}$ at $180 \mathrm{~K}$ (see the lowest spectrum in Fig. 7) the spectra are better resolved than after dosing at 80 K (Fig. 5). The $\mathrm{N}_{2}$ losses are no longer observed since chemisorbed $\mathrm{N}_{2}$ is not stable at this temperature. The strong $\mathrm{N}_{2}$ peak at $42 \mathrm{meV}$ in Fig. 5 has vanished and only a weak peak at $44 \mathrm{meV}$ is left. This loss is probably due to a librational mode since at this energy such a mode has been observed for thicker layers on $\mathrm{Ru}(0001){ }^{8}$ At $15.5 \mathrm{meV}$, well 
TABLE I. Vibrational energies in units of $\mathrm{meV}$ for $\mathrm{NH}_{x}(x=0 \cdots 3)$ on $\mathrm{Ru}(11 \overline{2} 1)$ compared to data from the literature for $\mathrm{Ru}(0001)$ (Ref. 8). Variation of energy with coverage is indicated by a dash with the coverage increasing from left to right. The vibrational modes are denominated as $T$ (translational mode); $\omega$ (wagging mode); $\rho$ (rocking mode); $\delta$ (bending or scissoring mode); $\nu$ (stretching mode). $s$, symmetric; $a$, asymmetric.

\begin{tabular}{lccccc}
\hline \hline & $\begin{array}{c}\mathrm{Ru}(0001) \\
\mathrm{Ref.} 8 \\
\mathrm{NH}_{3}\end{array}$ & $\begin{array}{c}\mathrm{Ru}(11 \overline{2} 1) \\
\text { This work } \\
\mathrm{NH}_{3}\end{array}$ & $\begin{array}{c}\mathrm{Ru}(11 \overline{2} 1) \\
\text { This work } \\
\mathrm{NH}_{2}\end{array}$ & $\begin{array}{c}\mathrm{Ru}(11 \overline{2} 1) \\
\text { This work } \\
\mathrm{NH}\end{array}$ & $\begin{array}{c}\mathrm{Ru}(11 \overline{1} 1) \\
\text { This work } \\
\mathrm{N}\end{array}$ \\
\hline$T_{Z}$ & $\ldots$ & 15 & 64 & 84 & $46,50,58$, \\
$\omega\left(\mathrm{NH}_{x}\right)$ & $42^{\mathrm{a}}$ & 44 & & & $61,69,75$ \\
$\rho\left(\mathrm{NH}_{x}\right)$ & 78 & $66-74$ & 163 & 89 & $\ldots$ \\
$\delta_{s}\left(\mathrm{NH}_{x}\right)$ & $143-133$ & $143-133$ & 189 & $\ldots$ & $\ldots$ \\
$\delta_{a}\left(\mathrm{NH}_{x}\right)$ & 197 & 194 & $\ldots$ & $\ldots$ & $\ldots$ \\
$\nu_{S}(\mathrm{~N}-\mathrm{H})$ & 407 & 400 & 408 & 410 & $\ldots$ \\
$\nu_{a}(\mathrm{~N}-\mathrm{H})$ & 421 & 420 & 419 & $\ldots$ & $\ldots$ \\
\hline \hline
\end{tabular}

${ }^{a}$ This mode was assigned to $T_{z}$ by Parmeter et al. (Ref. 9).

separated from the elastic peak, a strong peak has developed. Since the intensity of this low-energy mode varies with coverage similarly as the other $\mathrm{NH}_{3}$ modes, we assign it to $T_{z}$, the frustrated translation perpendicular to the surface. With decreasing $\theta_{\mathrm{NH}_{3}}, T_{z}$ shifts from 15.5 to $11 \mathrm{meV}$ (at $290 \mathrm{~K}$ ).

There is another new loss at $157 \mathrm{meV}$ which cannot be attributed to a known vibration. A detailed analysis of the HREEL spectra of atomic hydrogen in Ref. 16 shows that it is not due to $\mathrm{H}$. From its appearance together with $T_{z}$ one may think that it is due to a combination loss of $\delta_{s}\left(\mathrm{NH}_{3}\right)$ at $137.7 \mathrm{meV}$ and $T_{z}$. The problem, however, arises that the energy is higher by $3.8 \mathrm{meV}$ compared to the simple sum of energies whereas one expects a smaller value due to anharmonicity. Also the intensity is too high. Therefore, we abandon this interpretation. Another possibility may be that a second, differently bonded $\mathrm{NH}_{3}$ species occurs. A similar observation was made for $\mathrm{Ru}(0001)$ recently. ${ }^{19}$ We cannot give a final answer here which we, however, do not consider as important since this weak peak does not influence our conclusions.

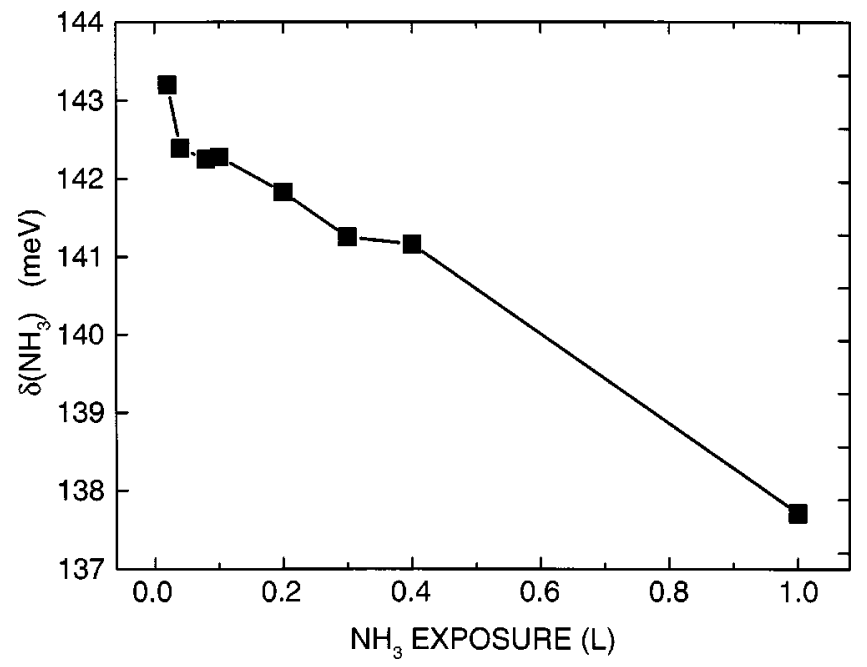

FIG. 6. The vibrational energies of the umbrella mode $\delta\left(\mathrm{NH}_{3}\right)$ vs exposure.

\section{Thermal dehydrogenation of $\mathrm{NH}_{3}$ probed by HREELS}

In order to examine the thermal dehydrogenation of $\mathrm{NH}_{3}, 1 \mathrm{~L} \mathrm{NH}_{3}$ was exposed at $180 \mathrm{~K}$. The respective HREEL spectra are shown in Fig. 7. After heating to $250 \mathrm{~K}$, all $\mathrm{NH}_{3}$ losses lose some intensity. The umbrella mode shifts to $140.4 \mathrm{meV}$ and loses about $20 \%$ in intensity. The temperature region between 180 and $250 \mathrm{~K}$ is characterized in TDS through the $\delta-\mathrm{H}_{2}$ state and the $\alpha_{2}-\mathrm{NH}_{3}$ state.

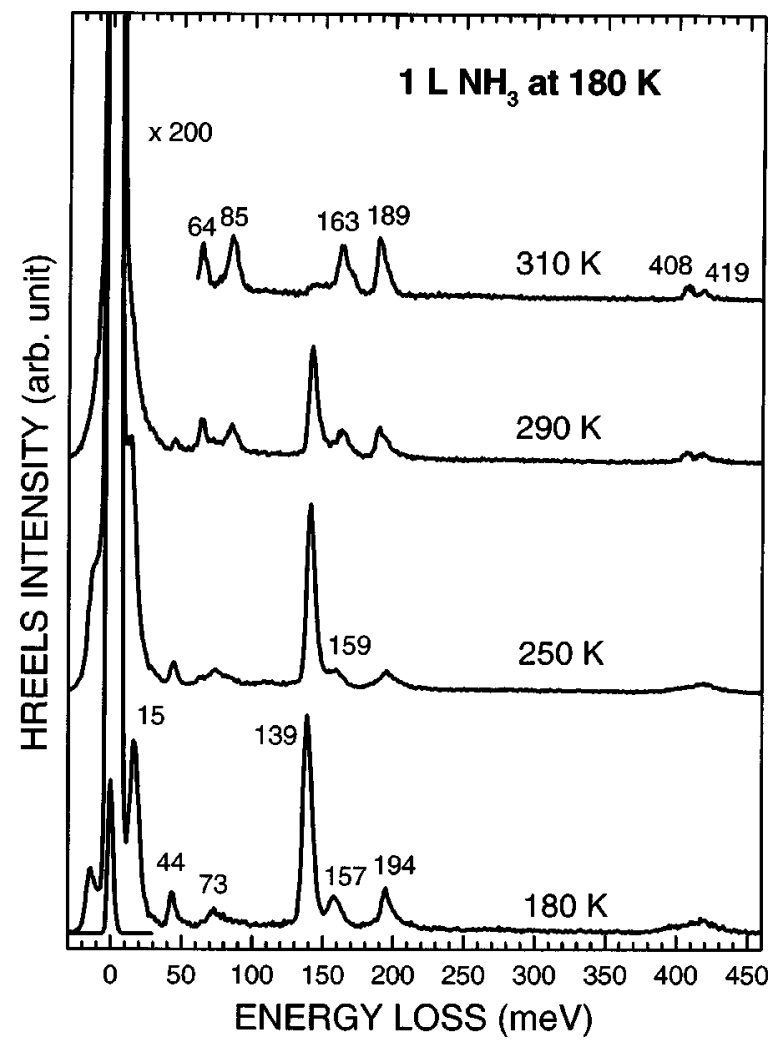

FIG. 7. HREEL spectra for an exposure of $1 \mathrm{~L} \mathrm{NH}_{3}$ on $\mathrm{Ru}(11 \overline{2} 1)$ at $180 \mathrm{~K}$. After exposure the sample was subsequently annealed to the indicated temperatures. The primary energy of the electrons was $2.5 \mathrm{eV}$. All spectra were recorded in specular geometry with an angle of incidence of $60^{\circ}$ with respect to the surface normal. 


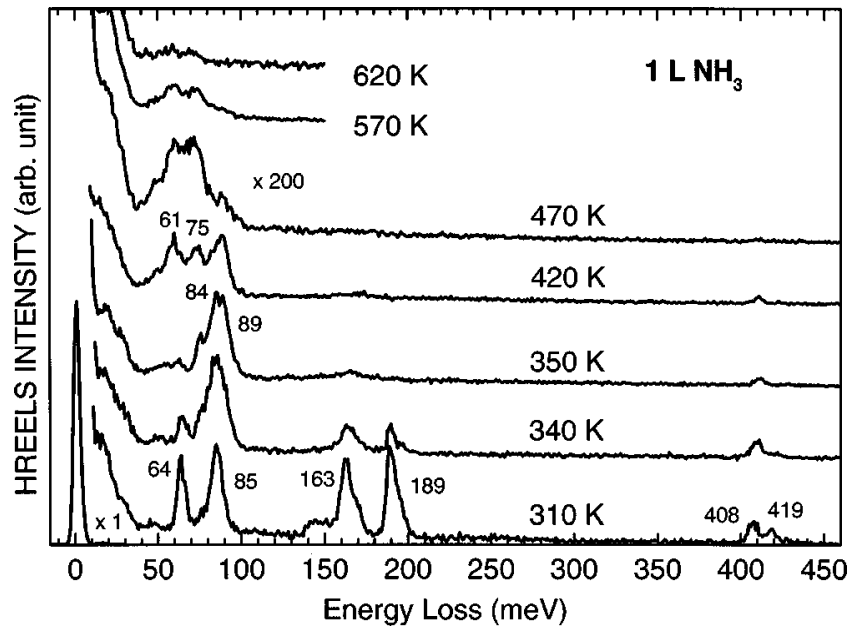

FIG. 8. HREEL spectra for an exposure of $1 \mathrm{~L} \mathrm{NH}_{3}$ at $180 \mathrm{~K}$. After exposure, the sample was subsequently annealed to the indicated temperatures. For the spectra recorded for $470 \mathrm{~K}$ and higher temperatures, the sample was exposed to $1 \mathrm{~L} \mathrm{NH}_{3}$ at $320 \mathrm{~K}$. The primary energy of the electrons was 2.5 $\mathrm{eV}$. All spectra were recorded in specular geometry with an angle of incidence of $60^{\circ}$ with respect to the surface normal.

Heating to $310 \mathrm{~K}$ lets the $\mathrm{NH}_{3}$ modes disappear and reveals new features at 64, 85, 163, and $189 \mathrm{meV}$. According to the calculation of Staufer et al. ${ }^{13}$ the mode at $163 \mathrm{meV}$ cannot be assigned to the $\mathrm{NH}$ bending mode as this mode has to be lower than $100 \mathrm{meV}$ in energy. Therefore, the mode at $163 \mathrm{meV}$ can only be due to $\mathrm{NH}_{2}$. This assignment is new and differs from that in our recent contribution. ${ }^{12}$ Besides $\mathrm{NH}_{2}$, also some amount of $\mathrm{NH}$ is found as demonstrated by its bending mode at $85 \mathrm{meV}$. So, the new assignment does not change our old assignment of the $\gamma-\mathrm{H}_{2}$ state as due to the

$$
2 \mathrm{NH}_{3, \mathrm{ad}} \rightarrow 2 \mathrm{NH}_{2, \mathrm{ad}}+\mathrm{H}_{2} \uparrow
$$

and

$$
\mathrm{NH}_{3, \mathrm{ad}} \rightarrow \mathrm{NH}_{\mathrm{ad}}+\mathrm{H}_{2} \uparrow
$$

reactions. The separation of $\mathrm{NH}$ and $\mathrm{NH}_{2}$ is better achieved for $\mathrm{Ru}(11 \overline{2} 0)^{20}$ and supports the assignment given here.

After desorption of $\mathrm{NH}_{3}$, the $\nu(\mathrm{N}-\mathrm{H})$ region is more structured exhibiting two rather sharp losses at 408 and 419 $\mathrm{meV}$ due to the symmetric and asymmetric $\mathrm{N}-\mathrm{H}$ stretching modes of $\mathrm{NH}_{2}$. This temperature region is characterized by $\gamma-\mathrm{H}_{2}$ as well as by $\alpha_{1}-\mathrm{NH}_{3}$. Thus, after heating to $310 \mathrm{~K}$, $\mathrm{NH}_{3}$ has disappeared completely, being either desorbed or dehydrogenated to $\mathrm{NH}_{2}$ or $\mathrm{NH}$.

Figure 8 exhibits HREEL spectra for further annealing to higher temperatures. The spectra at $310 \mathrm{~K}$ in Figs. 7 and 8 are from the same data set. By heating to $350 \mathrm{~K}$ the peaks at $64,163,189$, and $419 \mathrm{meV}$ disappear which indicates that $\mathrm{NH}_{2}$ is not present at the surface anymore. Besides the lowlying modes, there are four modes left at 74, 84, 89, and 412 $\mathrm{meV}$ for $\mathrm{NH}$. The existence of $\mathrm{NH}$ on the surface is proven by the $\nu(\mathrm{N}-\mathrm{H})$ loss at $412 \mathrm{meV}$ and the $\alpha-\mathrm{H}_{2}$ state at $420 \mathrm{~K}$ in TDS which was assigned to dehydrogenation of $\mathrm{NH}$. The peak at $74 \mathrm{meV}$ is probably due to $\mathrm{N}$. The peaks at 84 and 89

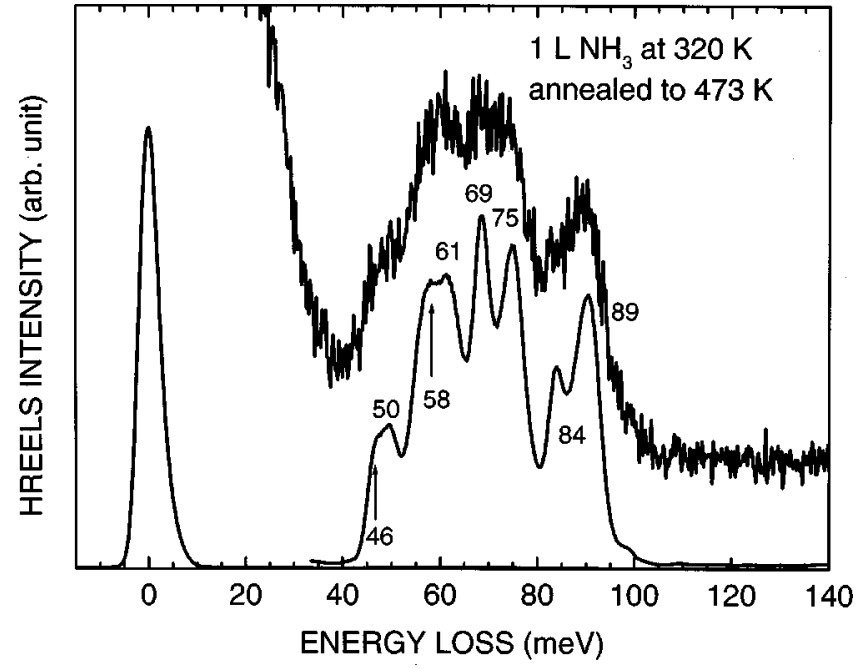

FIG. 9. HREEL spectra for $1 \mathrm{~L} \mathrm{NH}_{3}$ exposed to $\mathrm{Ru}(11 \overline{2} 1)$ at $320 \mathrm{~K}$ and subsequent annealing to $470 \mathrm{~K}$. The noisy line is the measured spectrum while the solid line between 30 and $100 \mathrm{meV}$ represents the result of a deconvolution for which the details are given in the text.

$\mathrm{meV}$ are assigned to the stretching and bending modes of $\mathrm{NH}$.

From the TD spectra shown in Fig. 4, it is found that at about $390 \mathrm{~K}$ the main amount of hydrogen has desorbed from the surface and only the weakly bonded $\alpha-\mathrm{H}_{2}$ state is left which is identified as due to the decomposition of $\mathrm{NH}$ by HREELS. By heating the sample to $420 \mathrm{~K}$, the losses attributed to $\mathrm{NH}$ at 84 and $89 \mathrm{meV}$ decrease in intensity. The losses at 61 and $75 \mathrm{meV}$ gain intensity and are attributed to $\nu(\mathrm{Ru}-\mathrm{N})$ modes of $\mathrm{N}$. By further heating to $470 \mathrm{~K}$, the NHrelated losses vanish nearly completely, and the $\nu(\mathrm{Ru}-\mathrm{N})$ losses form a band between 50 and $75 \mathrm{meV}$. To study this band in detail we have used a maximum-entropy deconvolution algorithm. ${ }^{21}$ The results are presented in the following section. At higher temperatures nitrogen desorbs from the surface which is completed at $620 \mathrm{~K}$. The $\mathrm{Ru}(11 \overline{2} 1)$ phonon at $20 \mathrm{meV}$ reappears. A summary of the vibrational frequencies of $\mathrm{NH}_{x}$ is given in Table $\mathrm{I}$.

\section{Deconvolution of the $\nu(\mathrm{Ru}-\mathrm{N})$ modes}

To derive more information about the vibrational frequencies of the $\nu(\mathrm{Ru}-\mathrm{NH})$ and $\nu(\mathrm{Ru}-\mathrm{N})$ modes a maximumentropy algorithm ${ }^{21}$ was used. This algorithm does not require any fit parameter and combines maximum-likelihood and maximum-entropy methods in a Bayesian framework. Figure 9 shows the HREEL spectrum following a $1 \mathrm{~L} \mathrm{NH}_{3}$ exposure at $320 \mathrm{~K}$ and annealing to $470 \mathrm{~K}$ and the spectrum after deconvolution by the maximum-entropy algorithm. The deconvoluted spectrum clearly resolves the two $\mathrm{NH}$ related losses at 84 and $89 \mathrm{meV}$. The broad band of $\mathrm{N}$ related losses gets resolved into six losses at 46, 50, 58, 61, 69, and 75 $\mathrm{meV}$. The deconvolution of other spectra for lower annealing temperatures shows the same loss energies of the main peaks but different intensities. The variety of $\nu(\mathrm{Ru}-\mathrm{N})$ related losses may be correlated with the variety of possible adsorption sites on the $\operatorname{Ru}(11 \overline{2} 1)$ surface as indicated in Fig. 1. 


\section{DISCUSSION}

The TD spectra of second- and multilayer $\mathrm{NH}_{3}$ on $\mathrm{Ru}(11 \overline{2} 1)$ differ only slightly from the respective TD spectra of $\mathrm{NH}_{3}$ on $\mathrm{Ru}(0001)$. The desorption temperatures are about $15 \mathrm{~K}$ lower which is within the limit of accuracy of absolute temperature calibration at surfaces.

The coverage of the $\mathrm{NH}_{3}$ monolayer can only be estimated since a LEED pattern of a $\mathrm{NH}_{3}$-derived superstructure is not observed and there are no easily reproducible nitrogen standards available in surface physics. $\mathrm{On} \mathrm{Ru}(0001)$, a $\mathrm{NH}_{3}$ monolayer is formed by dosing $1 \mathrm{~L} \mathrm{NH}_{3}{ }^{8}$ and a coverage of $\theta_{\mathrm{NH}_{3}}=0.25$ is estimated in accordance with the $2 \times 2$ LEED pattern. Assuming the same sticking coefficient for $\mathrm{NH}_{3}$ on $\mathrm{Ru}(11 \overline{2} 1)$, an exposure of $1 \mathrm{~L}$ would formally result in a coverage of $\theta_{\mathrm{NH}_{3}}=0.89$. The different coverage for the same dose and sticking coefficient arises from the different atom densities in the uppermost layer for $\mathrm{Ru}(0001)$ (15.7 $\left.\times 10^{14} \mathrm{~cm}^{-2}\right)$ and $\mathrm{Ru}(11 \overline{2} 1)\left(4.7 \times 10^{14} \mathrm{~cm}^{-2}\right)$. Given the physical size of $\mathrm{NH}_{3}$ (lateral diameter for an upright $\left.\mathrm{NH}_{3} \approx 3.6 \AA\right)$ and the length of the vector of the $\mathrm{Ru}(11 \overline{2} 1)$ $1 \times 1$ unit cell of $4.69 \AA$, it is very likely that a coverage of $\theta_{\mathrm{NH}_{3}}=1.0$ is reached following an exposure of $1 \mathrm{~L}$ at $180 \mathrm{~K}$. At this coverage, $\mathrm{NH}_{3}$ has still ample space to freely rotate and bend around its adsorption site.

HREELS demonstrates that $\mathrm{NH}_{3}$ does not dissociate on $\mathrm{Ru}(11 \overline{2} 1)$ for adsorption temperatures $\leqslant 180 \mathrm{~K}$, but adsorbs molecularly and builds-up mono- and multilayers as known for $\mathrm{Ru}(0001)$. For the $\mathrm{NH}_{3}$ monolayer, the vibrational spectra, known from the $\mathrm{Ru}(0001)$ surface $^{8}$ (see Table I), are reproduced. Only, a translation mode $T_{z}$ at $15.5 \mathrm{meV}$ is newly resolved. As this loss is very intensive and dipole active, we assign it to the frustrated translation perpendicular to the surface. This new interpretation was recently introduced by Widdra et al. ${ }^{19}$ for $\mathrm{Ru}(0001)$ although in their spectra this mode was ten times weaker then the umbrella mode. In our case, $T_{z}$ is of the same intensity as the umbrella mode making our assignment even more convincing. This mode was not observed by Parmeter et $_{\text {al. }}{ }^{8}$ due to the limited energy resolution at that time. Their assignment of a weak mode at $42 \mathrm{meV}$ as due to $T_{z}$ is not correct according to our and Widdra's experiments. We have not included this value, therefore, in Table I. Interestingly, Parmeter et al. observed the mode at $42 \mathrm{meV}$ only in off-specular direction which fits well to our assignment of this mode to a librational (wagging) mode.

During growth of the monolayer at $80 \mathrm{~K}$ (see Fig. 5), $T_{z}$ is not observed due to lacking energy resolution, coadsorption of $\mathrm{N}_{2}$ and $\mathrm{H}_{2}$, and probably some disorder in the adlayer. After heating to $180 \mathrm{~K}$ (see Fig. 7) these problems seem to be solved and the spectrum becomes better resolved. After annealing to $250 \mathrm{~K}$ the $\mathrm{NH}_{3}$ spectrum is not changed; $T_{z}$ is shifted from 15.5 to $11.2 \mathrm{meV}$ and $\delta_{s}$ from 139 to 142 $\mathrm{meV}$. Both effects are due to a change in coverage and may be identified as due to dipole-dipole interaction in case of $T_{z}$ and Stark effect in case of $\delta_{s}$. Two monolayer states which may be inferred from TDS are not disclosed by HREELS, so that the split into the $\alpha_{1}$ and $\alpha_{2}$ states is assigned to repulsive lateral interaction.
Following an exposure of $0.3 \mathrm{~L}, \mathrm{NH}_{3}$ is fully dissociated upon heating. From TDS we derived that the sticking coefficient of $\mathrm{NH}_{3}$ is constant for an exposure between 0.3 and 1 L. It is reasonable to assume that this holds also for an exposure below $0.3 \mathrm{~L}$. Therefore, we assume $\theta_{\mathrm{NH}_{3}}=0.3$ for an exposure of $0.3 \mathrm{~L}$, i.e., one molecule in about every third $1 \times 1$ unit cell. For an exposure $\leqslant 0.3 \mathrm{~L}$, only dissociation and for an exposure $>0.3 \mathrm{~L}$ dissociation and desorption are observed in parallel if one raises the sample temperature. How much $\mathrm{NH}_{3}$ is decomposed is a question of the two competing channels of desorption and dehydrogenation rather than of a vanishing reactivity of the surface at a given (rather small) coverage of dehydrogenation products.

For $\mathrm{NH}_{3}$ dehydrogenation two reaction intermediates are expected namely $\mathrm{NH}$ and $\mathrm{NH}_{2}$. We have observed the following four steps of the dehydrogenation which manifest themselves in $\mathrm{H}_{2}$ desorption states $\left(\alpha-\mathrm{H}_{2}\right.$ to $\left.\delta-\mathrm{H}_{2}\right)$ and in HREELS:

$$
\begin{array}{llll}
\gamma-\mathrm{H}_{2} & \text { at } 320 \mathrm{~K}: & 2 \mathrm{NH}_{3, \mathrm{ad}} \rightarrow 2 \mathrm{NH}_{2, \mathrm{ad}}+\mathrm{H}_{2} \uparrow, \\
\beta-\mathrm{H}_{2} & \text { at } 360 \mathrm{~K}: & 2 \mathrm{NH}_{2, \mathrm{ad}} \rightarrow 2 \mathrm{NH}_{\mathrm{ad}}+\mathrm{H}_{2} \uparrow, \\
\alpha-\mathrm{H}_{2} & \text { at } 420 \mathrm{~K}: & 2 \mathrm{NH}_{\mathrm{ad}} \rightarrow 2 \mathrm{~N}_{\mathrm{ad}}+\mathrm{H}_{2} \uparrow, \\
\delta-\mathrm{H}_{2} & \text { at } 220 \mathrm{~K}: & \mathrm{NH}_{3, \mathrm{ad}}+2 \mathrm{H}_{\mathrm{ad}} \rightarrow \mathrm{NH}_{3} \uparrow+\mathrm{H}_{2} \uparrow,
\end{array}
$$

The separation of these states is not complete, since we observe from both, TDS and HREELS, that at the $\gamma-\mathrm{H}_{2}$ release, $\mathrm{NH}_{2}$ and also $\mathrm{NH}$ is formed and at the $\beta-\mathrm{H}_{2}$ release $\mathrm{NH}$ and also $\mathrm{N}$ is formed. The amount of released $\mathrm{H}_{2}$ decreases from the $\gamma$ - to the $\beta$ - to the $\alpha$-state. The barrier for $\mathrm{NH}_{3}$ desorption decreases with coverage. For the full monolayer the barrier for desorption is lower than that for dehydrogenation. When the dehydrogenation begins at $280 \mathrm{~K}$ an estimated amount of about $2 / 3$ of the $\mathrm{NH}_{3}$ monolayer is desorbed already. This is the more fortuitous reason of why only about $1 / 3$ of a $\mathrm{NH}_{3}$ monolayer is decomposed.

The hydrogen TD spectra during dehydrogenation of $\mathrm{NH}_{3}$ give some insight into the dehydrogenation reaction. At an exposure of $0.3 \mathrm{~L}$ the four desorption states are fully developed. For the lowest $\mathrm{NH}_{3}$ exposure $(0.04 \mathrm{~L})$ a surprisingly strong $\mathrm{H}_{2}$ desorption is observed. This is mainly due to $\mathrm{H}_{2}$ adsorbed from the residual gas before and during exposure of $\mathrm{NH}_{3}$ which cannot be avoided for this reactive $\mathrm{Ru}$ surface even at a background pressure of $3 \times 10^{-11}$ mbar. This hydrogen desorbs together with $\mathrm{NH}_{3}$. The desorption temperature of $220 \mathrm{~K}$ is smaller than that found for first 0.3 monolayer of hydrogen on the bare surface. Thus, $\mathrm{NH}_{3}$ destabilizes coadsorbed hydrogen. This is similar to $\mathrm{N}+\mathrm{H}$ coadsorption on $\mathrm{Ru}(0001)$; for fractions of $0.26-0.37$ of a $\mathrm{N}$ monolayer, some part of the hydrogen is strongly destabilized. ${ }^{22}$ At a first look the size of the hydrogen signal in Fig. 4 is surprisingly large. It is understood, however, considering that at those temperatures, for which the dehydrogenation begins, $\mathrm{NH}_{3}$ as well as hydrogen is already largely destabilized. Therefore, most of the hydrogen, split off the $\mathrm{NH}_{x}$, desorbs immediately. The dehydrogenation of $0.3 \mathrm{ML}$ of $\mathrm{NH}_{3}$ produces $0.3 \mathrm{ML}$ of $\mathrm{N}$ and $0.9 \mathrm{ML}$ of $\mathrm{H}$, of which the latter one desorbs immediately. 
TABLE II. Vibrational energies in units of $\mathrm{meV}$ for $\mathrm{NH}_{2} X, X$ as indicated. The vibrational modes are denominated as $T$ (translational mode); $\tau$ (twisting mode); $\omega$ (wagging mode); $\rho$ (rocking mode); $\delta$ (bending mode); $\nu$ (stretching mode). $s$, symmetric; $a$, asymmetric.

\begin{tabular}{lccc}
\hline \hline & $\begin{array}{c}\mathrm{NH}_{2} \mathrm{CHO} \\
\text { gas phase } \\
\text { (Ref. 23) }\end{array}$ & $\begin{array}{c}\mathrm{NH}_{2} \mathrm{CO} \\
\text { on } \mathrm{Ru}(0001) \\
\text { (Ref. 24) }\end{array}$ & $\begin{array}{c}\mathrm{NH}_{2} \\
\text { on } \mathrm{Ru}(11 \overline{2} 1) \\
\text { this work }\end{array}$ \\
\hline$T_{z}$ & $\ldots$ & $\ldots$ & 64 \\
$\tau$ & 36 & $\ldots$ & $\ldots$ \\
$\omega$ & 75 & 103 & $\ldots$ \\
$\rho$ & 131 & $\mathrm{a}$ & 163 \\
$\delta$ & 194 & $\mathrm{a}$ & 189 \\
$\nu_{a}(\mathrm{~N}-\mathrm{H})$ & 439 & $417^{\mathrm{b}}$ & 419 \\
$\nu_{s}(\mathrm{~N}-\mathrm{H})$ & 428 & $417^{\mathrm{b}}$ & 408 \\
\hline \hline
\end{tabular}

${ }^{\mathrm{a}} 4$ peaks are found at $196,170,161$, and $126 \mathrm{meV}$ due to $\nu_{s}(\mathrm{NCO})$, $\nu_{a}(\mathrm{NCO}), \delta\left(\mathrm{NH}_{2}\right)$, and $\rho\left(\mathrm{NH}_{2}\right)$ without specific mode assignments.

${ }^{\mathrm{b}} \nu_{s}, \nu_{a}$ not resolved.

The reaction intermediate $\mathrm{NH}_{2}$ is found on $\mathrm{Ru}(11 \overline{2} 1)$ in a temperature range between 290 and $340 \mathrm{~K}$. Initiated by the calculations of Staufer et al., ${ }^{13}$ we newly assign the $\mathrm{NH}_{2}$ modes (see Table II). Our assignment is supported by vibrational data from gas phase ${ }^{23}$ and adsorbed ${ }^{24}$ formamide $\left(\mathrm{NH}_{2} \mathrm{CHO}\right)$ which contains an end-standing $\mathrm{NH}_{2}$ Group. Whereas the identification of the $\mathrm{NH}_{2}$ group from the stretching and bending modes is quite convincing, the assignment of the librational (rocking, wagging, twisting) modes is still not quite obvious. However, if one believes that, during adsorption, the wagging mode $\omega$ shifts from 75 (gas phase) to $103 \mathrm{meV}$ [for $\mathrm{NH}_{2} \mathrm{CO}$ on $\mathrm{Ru}(0001)$, see Table II], one also may believe in a shift of the rocking mode energy from its gas phase value of 131 to a value of $163 \mathrm{meV}$ for the $\mathrm{NH}_{2}$ intermediate in our case.

The energy barriers for the processes (2)-(4) continuously increase. Assuming first-order reactions and a prefactor of $10^{13}$ per s leads to an activation barriers of $88 \mathrm{~kJ} / \mathrm{mol}$ for reaction (2), $100 \mathrm{~kJ} / \mathrm{mol}$ for (3), and $117 \mathrm{~kJ} / \mathrm{mol}$ for (4). This is the reason of why we can observe all reaction intermediates mainly sequentially. On $\mathrm{Ru}(0001)$ and also in microkinetic modeling of gas flow experiments ${ }^{25}$ the barrier for (3) is smaller than for (2) and $\mathrm{NH}_{2}$ can not be stabilized in $\mathrm{NH}_{3}$ dehydrogenation. The amount of released hydrogen decreases gradually from the $\gamma$ - to the $\beta$ - and to the $\alpha$-state. This can be understood by assuming that in each dehydrogenation step some of the reactants proceed immediately further to the following step.

The $\mathrm{N}$ coverage can be derived from the $\mathrm{NH}_{3}$ coverage. Since an ammonia coverage of $\theta_{\mathrm{NH}_{3}}=0.3$ fully dissociates, the coverage of nitrogen is also $\theta_{\mathrm{N}}=0.3$. Compared to the maximum nitrogen coverage of $\theta_{\mathrm{N}}=0.47$ achieved on $\mathrm{Ru}(0001),{ }^{26}$ this coverage is relatively small keeping in mind the different sizes of the unit cells. It is surprising that six slightly different $\nu(\mathrm{Ru}-\mathrm{N})$ stretch frequencies are observed although $\theta_{\mathrm{N}}$ is rather small. We conclude that the adsorption energies at the different sites within the $1 \times 1$ unit cell are not very different. Therefore, the entropy term in the free enthalpy of adsorption may prevent an ordering within the adlayer. Instead from unit cell to unit cell, $\mathrm{N}$ occupies different sites. First attempts to increase $\theta_{\mathrm{N}}$ through $\mathrm{NH}_{3}$ decomposi- tion failed. The number of six different $\nu(\mathrm{Ru}-\mathrm{N})$ frequencies nicely correlates with six different threefold-hollow sites in the unit cell (see Fig. 1).

\section{CONCLUSION}

At $80 \mathrm{~K} \mathrm{NH}_{3}$ adsorbs in mono- and multilayers on $\operatorname{Ru}(11 \overline{2} 1)$. The observed vibrations are essentially identical to those found for $\mathrm{Ru}(0001)$. For the monolayer we newly assign the perpendicular translation mode $T_{z}$ at 11.2-15 $\mathrm{meV}$. This assignment is in agreement with that given recently for $\mathrm{Ru}(0001) .{ }^{19}$ Whereas in TDS two monolayer states are observed, there is no indication of two different states found in the HREEL spectra.

The $\mathrm{Ru}(11 \overline{2} 1)$ surface is more reactive than $\mathrm{Ru}(0001)$. After adsorption at temperatures $\leqslant 180 \mathrm{~K}$, an amount of 0.3 monolayer of $\mathrm{NH}_{3}$ decomposes completely into $\mathrm{N}$ and $\mathrm{H}$ during annealing to $470 \mathrm{~K}$. That only a fraction $x$ of a monolayer is decomposed, is simply due to the fact that dehydrogenation starts only at about $280 \mathrm{~K}$, at which temperature about a $1-x$ fraction of a monolayer is already desorbed. At higher coverage, desorption and dehydrogenation occur one after the other and the dehydrogenation part does not increase.

The reaction intermediates $\mathrm{NH}_{2}$ and $\mathrm{NH}$ were identified using HREELS. The new assignment of the $\mathrm{NH}_{2}$ modes is based on a recent calculation. ${ }^{13}$ Interestingly, on $\mathrm{Ru}(11 \overline{2} 1)$ the activation barrier for hydrogen abstraction from $\mathrm{NH}_{x}$ increase stepwise when $x$ decreases. This made it possible to identify the dehydrogenation steps.

\section{ACKNOWLEDGMENTS}

The authors thank Professor G. Ertl for enduring support and P. Geng for dedicated technical assistance. One of the authors (Y.W.) is grateful to the German academic exchange service (DAAD) for a stipend.

${ }^{1}$ S. R. Tennison, in Catalytic Ammonia Synthesis, edited by J. R. Jennings (Plenum, New York, 1991), p. 303; K. Aika, Angew. Chem. Int. Ed. Engl. 25, 558 (1986).

${ }^{2}$ G. Ertl, in Catalytic Ammonia Synthesis, edited by J. R. Jennings (Plenum, New York, 1991), p. 109.

${ }^{3}$ L. R. Danielson, M. J. Dresser, E. E. Donaldson, and J. T. Dickinson, Surf. Sci. 71, 599 (1978).

${ }^{4}$ L. R. Danielson, M. J. Dresser, E. E. Donaldson, and D. T. Sandstrom, Surf. Sci. 71, 615 (1978)

${ }^{5}$ C. Benndorf and T. Madey, Surf. Sci. 135, 164 (1983).

${ }^{6}$ W. Tsai and W. H. Weinberg, J. Phys. Chem. 91, 5302 (1987).

${ }^{7}$ C. Egawa, S. Naito, and K. Tamaru, Surf. Sci. 138, 279 (1984).

${ }^{8}$ J. E. Parmeter, Y. Wang, C. B. Mullins, and W. H. Weinberg, J. Chem. Phys. 88, 5225 (1988)

${ }^{9}$ H. Rauscher, K. L. Kostov, and D. Menzel, Chem. Phys. 177, 473 (1993).

${ }^{10}$ I. Bassignana, K. Wangmann, J. Küppers, and G. Ertl, Surf. Sci. 175, 22 (1986).

${ }^{11}$ H. Shi, K. Jacobi, and G. Ertl, J. Chem. Phys. 102, 1432 (1995).

${ }^{12}$ H. Dietrich, K. Jacobi, and G. Ertl, Surf. Sci. 352-354, 138 (1996).

${ }^{13}$ M. Staufer, K. M. Neyman, P. Jakob, V. A. Nasluzov, D. Menzel, and N. Rösch, Surf. Sci. 369, 300 (1996).

${ }^{14} \mathrm{H}$. Ibach, Electron Energy Loss Spectroscopy-The Technology of High Performance (Springer, New York, 1991).

${ }^{15}$ J. Wang, Y. Wang, and K. Jacobi, Surf. Sci. (to be published).

${ }^{16}$ C. Y. Fan and K. Jacobi, Surf. Sci. 21, 482 (2001). 
${ }^{17}$ H. Shi, K. Jacobi, and G. Ertl, J. Chem. Phys. 99, 9248 (1993).

${ }^{18}$ H. Dietrich, K. Jacobi, and G. Ertl, J. Chem. Phys. 106, 9313 (1997).

${ }^{19}$ W. Widdra, T. Moritz, K. L. Kostov, P. König, M. Staufer, and U. Birkenheuer, Surf. Sci. 430, L558 (1999).

${ }^{20} \mathrm{Y}$. Wang and K. Jacobi (in preparation).

${ }^{21}$ B. G. Frederick, T. S. Jones, P. D. A. Pudney, and N. V. Richardson, J. Electron Spectrosc. Relat. Phenom. 64/65, 825 (1993).
${ }^{22}$ D. C. Seets, M. C. Wheeler, and C. B. Mullins, J. Chem. Phys. 103, 10399 (1995).

${ }^{23}$ S. T. King, J. Phys. Chem. 75, 405 (1971).

${ }^{24}$ J. E. Parmeter, U. Schwalke, and W. H. Weinberg, J. Am. Chem. Soc. 110, 53 (1988).

${ }^{25} \mathrm{H}$. Hinrichsen, Catal. Today 53, 177 (1999).

${ }^{26}$ H. Dietrich, K. Jacobi, and G. Ertl, J. Chem. Phys. 105, 8944 (1996). 